\title{
Tools to support maintenance strategies under soft soil conditions
}

\author{
J. W. M. Lambert ${ }^{1}$, J. J. van Meerten ${ }^{1}$, M. P. Woning ${ }^{1}$, M. J. Eijbersen ${ }^{2}$, and M. Huber ${ }^{1}$ \\ ${ }^{1}$ Deltares, Delft, the Netherlands \\ ${ }^{2}$ CROW, Ede, the Netherlands \\ Correspondence to: J. W. M. Lambert (john.lambert@deltares.nl) \\ Published: 12 November 2015
}

\begin{abstract}
Costs for maintenance of infrastructure in municipalities with soft soil underground conditions, are estimated to be almost $40 \%$ higher than in others. As a result, these municipalities meet financial problems that cause overdue maintenance. In some cases municipalities are even afraid to be unable to offer a minimum service level in future.

In common, traditional practice, roads and sewerage systems have been constructed in trenches that consist of sandy material that replaces the upper meters of the soft soil. Under influence of its weight, this causes accelerated settlements of the construction. A number of alternative constructions have been developed, e.g. using light-weight materials to limit settlement velocity.

In order to limit future maintenance costs, improvement of maintenance strategies is desired. Tools have been and will be developed to support municipalities in improving their maintenance strategies and save money by doing that.

A model (BALANS) that weighs the attractiveness of alternative solutions under different soil, environmental and economic circumstances, will be presented.
\end{abstract}

\section{Introduction}

The presence of soft soils near the surface is common in many Delta areas in the world. These areas are attractive for agricultural activities because of their fertility, but also population concentrates in these zones because of their favourable transport situation near the sea and near the mouth of rivers.

As a result, the soils in Delta eras are commonly intensively used for agriculture, housing, industrial zones and transport infrastructure. These different activities require different, sometimes conflicting conditions. Especially water management to optimize agricultural production and groundwater abstraction in order to supply inhabitants with drinking water and for industrial water supply, may lead to subsidence and damage to other interests, such as to houses, buildings and line infrastructure such as railways, roads and pipelines.

In the Netherlands, soft soils cover a big part of the country and the mentioned activities concentrate in these soft soil areas. The thickness of the Holocene peat and clay layers is variable and may reach up to $15 \mathrm{~m}$ of extremely soft soil.
Municipalities in these regions suffer high costs for maintenance of their infrastructure. Alternative constructions have been developed and new alternatives will be developed. In this paper, a tool to support municipalities and other infrastructure managers in their design and maintenance management is described. The tool has been developed by Deltares, Delft Cluster (a consortium of knowledge institutes in the Netherlands) and ISMH (Community of Soft Soil Municipalities)

\section{Traditional solution}

Municipal roads and sewerage systems were originally constructed by digging a trench into the soft soil, filling the trench with sand and then cover the trench with a road construction. After the pavement and foundation have settled more than about $0.40 \mathrm{~m}$ a reconstruction takes place by lifting the surface with sand again (Fig. 1). 


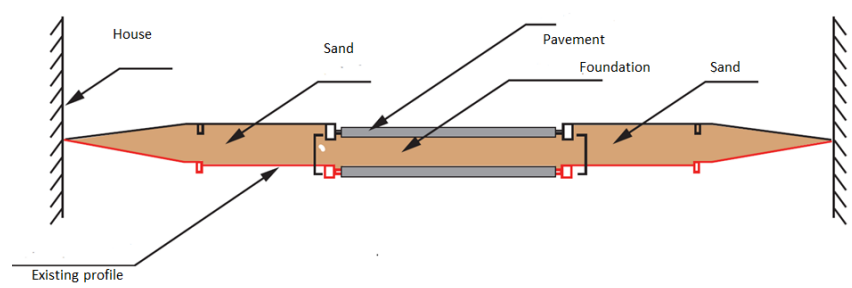

Figure 1. Traditional solution.

As the volumetric weight of sand (e.g. $19 \mathrm{kN} \mathrm{m}^{-3}$ ) is much higher than that of the excavated peat (e.g. $11 \mathrm{kNm}^{-3}$ ) or clay, the underlying peat or clay layers are burdened and sink rapidly after road-construction and the infrastructure may need frequent maintenance and re-construction.

\section{Alternative solutions}

In the past decades many alternative road foundation constructions have been developed and have been applied. Especially light materials, such as Bims (volcanic porous rock), flugsand, and foamed glass have been applied, but also constructions consisting of light weight blocks or panels, such as EPS (polystyrene) and strengthened sludge. Also under piled constructions, such as the geosynthetic reinforced piled embankment, have been applied. A schematic cross-section of this solution is given in Fig. 2.

\section{Tools for management support}

Municipalities need support to design new roads (and sewerage systems) as well as long term maintenance and reconstruction strategies in order to save public money and to minimize environmental impact. A design tool (model BALANS) was developed to support municipalities to choose the system that fits best their circumstances and requirements. Also, a tool to support their management strategy is under construction. This tool will be based on InSAR-observations.

Besides this, a pilot project in the village Kamerik (Municipality Woerden) is under construction. In the pilot, four different foundation constructions will be constructed and monitored in order to develop objective methods to compare the performance of the different constructions. In this paper, the BALANS tool and the tool to support the management strategy are described

\section{Balans}

Balans (Dutch for: Balance) enables to assess the financial and environmental consequences of different alternative road constructions, taking into consideration geotechnical and hydrological circumstances, as well as the governing boundary conditions, such as cables, pipelines, sewerage systems,

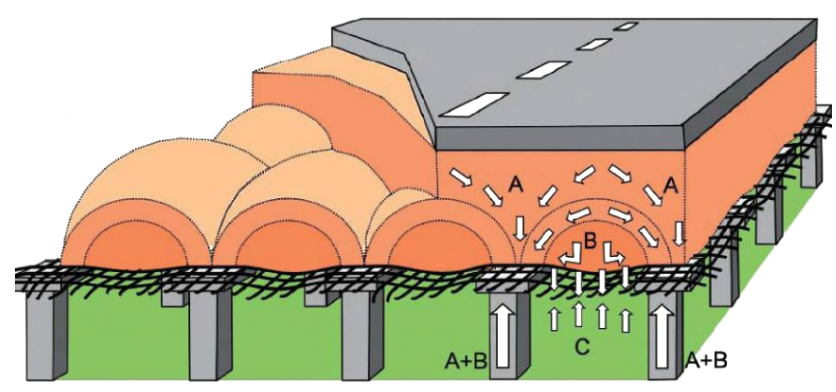

Figure 2. Load distribution in a reinforced piled embankment.

houses and their foundations, hindrance during construction, etc.

In the first place, the present geological, geotechnical (in terms of settlement parameters) and geohydrological (groundwater levels) must be imported in the model.

Then, the chosen construction has to be imported in terms of: excavation level, planned future construction level and volumetric weight of all construction materials. Balans is coupled with a material database that derives standard costs and environmental costs of the applied materials and proposes the volumetric weight to be applied (this can be adapted manually).

Given the proposed construction and materials, the program predicts the settlements and derives from these expected costs for maintenance and reconstruction during a user defined lifetime (e.g. 50 or 60 years). These costs are presented as Net Contant Value (NCV), taking into account a user defined interest percentage. Figure 3 gives an example of the calculated settlements and proposed maintenance periods.

BALANS is also coupled with a database, that contains LCA's (Life Cycle Analysis) of a number of materials; import of the amounts of the used materials enables to calculate the environmental costs of the proposed construction, also in terms of NCV.

Besides costs, other circumstances may influence the optimal choice. These circumstances are very much depending of local conditions, such as the presence of houses and their foundations, requirements in terms of availability of the road and other boundary conditions, such as the presence of sewerage systems, subsoil cables and pipelines, possible risks etc. The user may define the weight of each of these mentioned topics.

BALANS is able to compare two or more possible constructions at once and presents the results in a diagram. Figure 4 shows such a diagram, which gives insight how decisions may depend from the weight that is given to each of the mentioned criteria. 


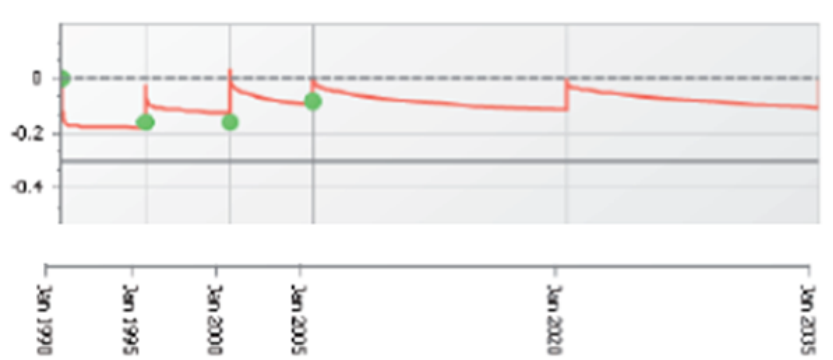

Figure 3. Predicted settlements and (green dots) predicted maintenance moments.

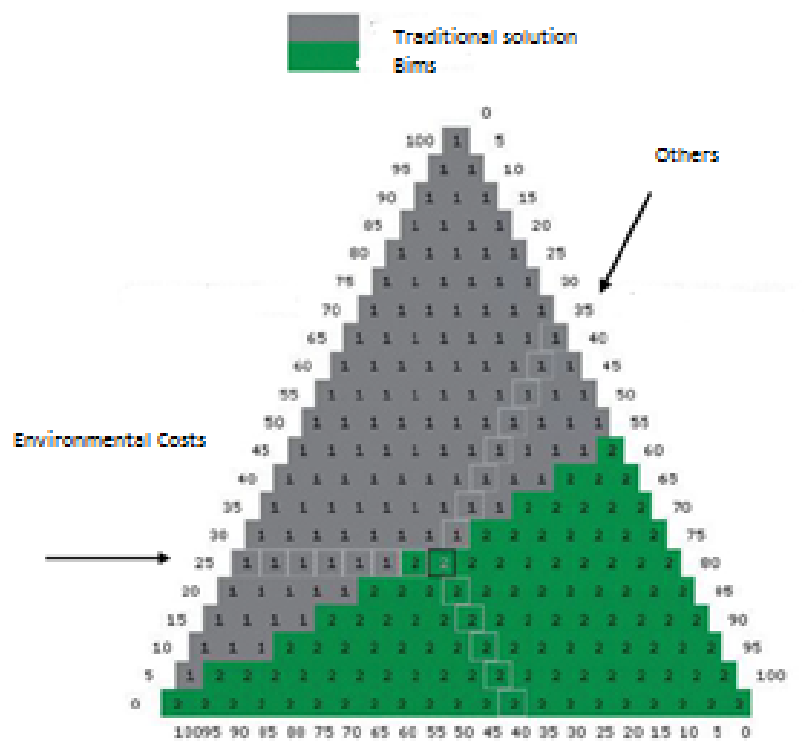

+ Stendard costs (NCV)

Figure 4. Output from BALANS, comparison of a traditional solution and a Bims construction.

\section{Test site Woerden (Kockengen)}

However many different alternative constructions and materials have been developed and applied in the Netherlands, there is still much misunderstanding and confusion about the applicability of the different solutions. The main reason is that no objective method exists to evaluate and, moreover, reconstructions after execution are rarely monitored.

At this moment, the municipality of Woerden is preparing the construction of a test site to compare foundations constructed with bims, foamed glass, sand and reinforced piled embankment.

The subsoil is consisting of very soft peat until a depth of about $6 \mathrm{~m}$ below surface. The roads were constructed in the seventies of the 20th century and have been settling about $0.50 \mathrm{~m}$ since then. As adjacent houses have been constructed on concrete piles, the difference in height between the houses

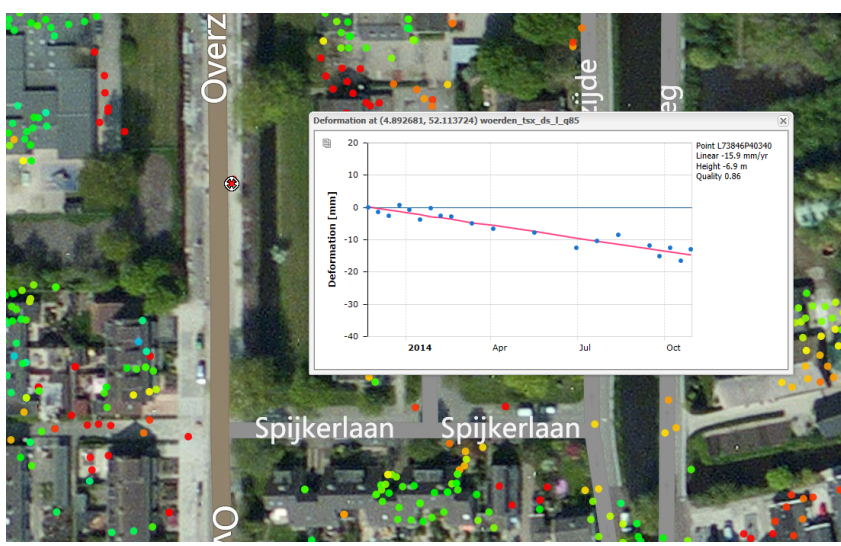

Figure 5. Example of present settlement observations by InSAR (SkyGEO).

and the road becomes unacceptable. Moreover, the road surface is approaching the groundwater level.

In the test site, the mentioned foundation constructions will be applied. During construction all activities and used materials will accurately be monitored, while - after construction - the future settlements of each construction will be monitored by means of InSAR, as well as by traditional levelling methods.

Figure 5 shows an example of the present settlements, observed by means of InSAR near the test location.

\section{Conclusions}

A model has been developed to compare possible alternative foundation constructions for municipal roads under soft soil conditions. The model takes into account not only the present construction costs, but also accounts with the expected maintenance and reconstruction costs in future. Difference is made between real costs, environmental costs and the influence of other boundary conditions. A test site, to compare the real future performance of different methods is under preparation and will be executed in Kamerik (Municipality of Woerden); besides traditional levelling, InSAR techniques will be applied for this comparison.

In our opinion, the discussed model is a useful tool to evaluate alternatives for road foundations under soft soil conditions. It makes clear that the cheapest construction may be the most expensive on the long term.

\section{References}

Deltares: Leidraad Balans (only available in Dutch). 